\title{
Terapias celulares: una nueva era en la batalla contra el cáncer
}

\author{
Diana Hernández y Alejandro Madrigal \\ Anthony Nolan. University College London, The Royal Free Hospital, Londres, Reino Unido
}

La terapia celular es el uso de las células como agentes terapéuticos; en ella pueden diferenciarse dos grandes áreas: una que involucra regeneración, sustitución o reemplazo de células funcionales (terapia con células madre) y otra relacionada con el empleo de células inmunológicas, que busca explotar las capacidades de estas como efectoras o supresoras del sistema inmune (inmunoterapia celular).

El uso de progenitores hematopoyéticos no es nuevo, data de hace más de 50 años y tal vez constituye el ejemplo de terapia celular más exitoso hasta la fecha. El trasplante de progenitores hematopoyéticos se efectúa con fines curativos en leucemias o linfomas, sin embargo, aún es un procedimiento con alta mortalidad dado que el paciente requiere antes altas dosis de quimioterapia o radiación para eliminar las células tumorales, acondicionar el nicho medular para albergar el injerto y ocasionar inmunosupresión para evitar el rechazo del injerto. A pesar de ello, el trasplante hematopoyético es relativamente común: anualmente se llevan a cabo 42000 procedimientos en todo el mundo y actualmente son más seguros.

Otro avance relevante es la manipulación de las células del injerto para mejorar el trasplante. Destacan dos procedimientos: el uso de injertos haploidénticos con la reducción de los linfocitos $T$ in vitro antes del trasplante y la expansión de células madre ex vivo. Este último ha sido aplicado específicamente a sangre del cordón umbilical, pues es la fuente más limitada en términos de números de células. Existen cuatro productos que han sido ensayados clínicamente con respuestas positivas:

- NiCord ${ }^{\circledR}$ de Gamida Cell (Israel) en fase III de ensayos clínicos. ${ }^{1,2}$

- MGTA-456 ${ }^{\circledR}$ de Magenta Therapeutics (Estados Unidos) en fase $\mathrm{I} / \mathrm{II} .^{3,4}$
- UM171 (ECL101) de ExCellThera (Canadá) en fase $1 / I .{ }^{5,6}$

- NLA101 de Nohla Therapeutics (Estados Unidos) en fase II. ${ }^{7,8}$

El uso de cordón umbilical para el trasplante de progenitores hematopoyéticos se incrementó hasta 2016, pues se demostró que tiene menos probabilidad de causar enfermedad de injerto contra huésped $(\mathrm{EICH})$, aun con compatibilidad de HLA menor a la necesaria cuando se usan células adultas y adicionalmente no causa complicaciones al donante. Sin embargo, principalmente por el alto costo y el retraso en el establecimiento del injerto ha sido reemplazado en los últimos dos años por los trasplantes haploidénticos. Nuevos estudios han demostrado que la expansión de células es un procedimiento seguro y bien tolerado y el tiempo requerido para el establecimiento del injerto es igual que el de las células adultas, lo que hace muy atractiva esta fuente de células madre.

Por otro lado, los tratamientos con células inmunológicas han tenido un gran empuje en la última década, utilizan la capacidad natural de estas células para destruir patógenos y células tumorales. La manipulación terapéutica del sistema inmune puede superar la morbilidad y mortalidad causadas por una deficiente inmunidad adaptativa y por tumores malignos resistentes a otros procedimientos terapéuticos, radioterapia quirúrgica o quimioterapia.

Las intervenciones para modular la reactividad inmune pueden ser valiosas para tratar enfermedades crónicas autoinmunes e inflamatorias y las medidas para proporcionar inmunidad adaptativa, activa 0 adoptiva son vitales para reducir la morbilidad y mortalidad de pacientes y receptores.

Las diferentes modalidades de trasplantes de órganos, tejidos y células, así como la eficacia de los
Fecha de recepción: 13-09-2018

Fecha de aceptación: 20-09-2018 DOI: 10.24875/GMM.18004687
Gac Med Mex. 2018;154:547-549

Disponible en PubMed www.gacetamedicademexico.com 
trasplantes de células madre hematopoyéticas para tratar hemopatías malignas pueden potenciarse mediante intervenciones dirigidas a proporcionar una reactividad inmune antitumoral adoptiva o generadora endógena. Los primeros ensayos clínicos para investigar la capacidad de los linfocitos T para detectar y eliminar células tumorales usaron linfocitos $T$ aislados de tumores de pacientes y expandidos in vitro. Estas células demostraron tener especificidad contra el tumor y en ciertos casos fueron eficaces en eliminarlo. Desafortunadamente, el aislamiento de clones y su expansión es laboriosa y en la mayoría de los casos resulta ser un procedimiento demasiado largo para ser de utilidad clínica.

El avance más importante tal vez ha sido el uso de las llamadas CAR-T cells (chimeric antigen receptor $T$ cells). ${ }^{9}$ Estas células, como su nombre lo indica, son linfocitos $T$ efectores cuyo papel es reconocer, atacar y destruir células cancerígenas o infectadas. Los linfocitos $T$ reconocen epítopos específicos en las células afectadas y las destruyen; este reconocimiento molecular, mediado por el receptor de célula $T$ en el contexto de HLA-clase I, puede ser manipulado usando ingeniería genética para crear clones de linfocitos $T$ que expresan un receptor quimera transgénico e identifican, por ejemplo, el antígeno CD19 ubicado exclusivamente en los linfocitos B y, por tanto, pueden ser utilizados para tratar a pacientes con síndromes linfoproliferativos de estirpe $B$, incluida la leucemia linfocítica crónica.

La Food and Drugs Administration ha aprobado dos terapias celulares compuestas de linfocitos $T$ transgénicos: Kymriah ${ }^{\circledast}$ de Novartis (Suiza), ${ }^{10}$ para el tratamiento de leucemia linfoblástica aguda B infantil, y Yescarta $^{\circledR}$ de Gilead (Estados Unidos), ${ }^{11}$ para el tratamiento del linfoma no-Hodgkin. Otras compañías y varios grupos académicos, tanto en Estados Unidos como en Europa, tienen programas clínicos avanzados en los que se emplean productos similares (por ejemplo, Cellectis, Celyad, Juno, Bluebird Bio).

Estas terapias celulares tienen el potencial para revolucionar el tratamiento del cáncer y han probado su efectividad en pacientes resistentes a otros tratamientos, erradicando rápidamente linfomas o leucemias con alta carga tumoral. Sin embargo, tienen varios problemas: actualmente solo pueden ser usadas contra leucemias o linfomas de estirpe B, y pueden provocar complicaciones neurológicas graves $\mathrm{y}$, principalmente, síndrome de liberación de citocinas, cuyo pronóstico es infausto. Por otro lado, su costo es muy alto: una dosis de Kymriah cuesta cerca de
500000 dólares americanos. A pesar de ello, esta revolucionaria modalidad contra el cáncer es real y ha impulsado el desarrollo de otras inmunoterapias, incluyendo el uso de células NK (natural killer) para el tratamiento en recaídas y células mesenquimales para el tratamiento de $\mathrm{EICH}$.

Las NK son células del sistema innato especializadas en reconocer y eliminar células que se han transformado en células tumorales o han sufrido infección viral, sin necesidad de reconocimiento previo o sensibilización, como sucede con los linfocitos T; esta propiedad puede aprovecharse para el tratamiento de hemopatías malignas, pero es necesario cultivar las células ex vivo para expandirlas y potenciar su actividad antitumoral.

En los últimos años varios estudios preclínicos y clínicos han demostrado la factibilidad de transferir células NK adaptativamente. Los estudios clínicos pueden ser divididos en dos: aquellos que las combinan con trasplante de progenitores hematopoyéticos y los que utilizan solo el trasplante de células NK. En el primer grupo se ha demostrado la seguridad de los procedimientos en la mayoría de los pacientes, sin toxicidad declarada, sin embargo, ha sido difícil probar su eficacia pues numerosos pacientes desarrollaron $\mathrm{EICH}$, causada por los linfocitos $\mathrm{T}$ en el injerto. Todos los estudios de trasferencia de células NK como terapia celular única demostraron ser seguros y la eficacia en cuanto a la reducción de la carga tumoral es aparente, por lo menos en los casos de hemopatías malignas, pero menos obvia en tumores sólidos. ${ }^{2}$

Mediante ingeniería genética, varios grupos han desarrollado células CAR-NK usando vectores similares a los empleados en la construcción de CAR-T cells, cuyo objetivo son las células que expresan CD19 (linfocitos B). Los CAR-NK atacan estas células, pero a diferencia de las células $T$ no necesitan tener HLA compatible y, por lo tanto, no causan EICH, lo que permite que los productos de las células NK puedan ser creados a partir de células de un donante no emparentado (alogénico), con lo que los costos de producción se reducen sustancialmente..$^{13}$

Por otro lado, se ha explorado ampliamente la utilidad de las células mesenquimales para el tratamiento de neoplasias y padecimientos autoinmunes como $\mathrm{EICH}$, lupus y esclerosis múltiple. Se ha establecido que ejercen su acción mediante la secreción de citocinas y otras moléculas con capacidades pro y antiinflamatorias y también regenerativas, más que por su capacidad de integración a los tejidos. Las 
ventajas de estas células es que tienen la capacidad de desplazarse por todo el cuerpo y pueden descargar sus citocinas en el lugar donde son requeridas, lo cual puede ser usado para llevar otras moléculas, incluyendo fármacos, a tejidos afectados por enfermedades o tumores. Actualmente hay más de 1000 estudios clínicos registrados en ClinicalTrials.gov que utilizan células mesenquimales y más de 15 compañías con productos basados en ellas para tratamientos clínicos. ${ }^{14}$

La evidencia sugiere que las terapias celulares tienen la capacidad de cambiar la forma de enfrentar las enfermedades, incluido el cáncer, pues por primera vez ofrecen la posibilidad de curación. Aún existen numerosos obstáculos, desde la obtención de las células primarias, la manufactura industrial de los productos celulares, su distribución y costo, hasta las complicaciones clínicas y efectos secundarios que todavía no han sido anticipados, sin embargo, todo parece indicar que son el futuro de la medicina.

\section{Bibliografía}

1. Horwitz ME, Chao NJ, Rizzieri DA, Long GD, Sullivan KM, Gasparetto C et al. Umbilical cord blood expansion with nicotinamide provides longterm multilineage engraftment. J Clin Invest. 2014;124(7):3121-3128

2. Horwitz ME, Cilloni D, Valcarcel D, Frassoni F, Boelens JJ, Jagasia M, et al. Nicord single unit expanded umbilical cord blood transplantation (UCBT): final results of a multicenter phase I/II trial. Blood. 2017;130 Suppl 1:847.
3. Wagner JE, Brunstein CG, DeFor TE, Boitano AE, McKenna D, Sumstad D, et al. Phase 2 trials with Mgta-456, single cord blood units (CBU) expanded with an aryl hydrocarbon receptor (AHR) antagonist, demonstrate uniform engraftment and rapid hematopoietic recovery in patients following myeloablative or non-myeloablative conditioning. Blood. 2017;130 Suppl 1:662

4. Wagner JE, Brunstein CG, Boitano AE, DeFor TE, McKenna D, Sumstad $D$, et al. Phase I/II trial of stemregenin-1 expanded umbilical cord blood hematopoietic stem cells supports testing as a stand-alone graft. Cell Stem Cell. 2016;18(1):144-155

5. Fares I, Chagaroui J, Gareau Y, Gingras S, Mayotte N, Csaszar E, et al. Pyrimidoindole derivatives are agonists of human hematopoietic stem cell self-renewal. Science 2014;345(6203):1509-1512.

6. Cohen S, Roy J, Lachance S, Marinier A, Roy DC, Delisle JS, et al. Single UM171 expanded cord blood transplant is feasible, safe, and permits transplantation of better HLA matched cords with very low transplant related mortality. Blood. 2017;130:658.

7. Delaney C, Heimfeld S, Brashem-Stein C, Voorhies $H$, Manger RL, Bernstein ID, et al. Notch-mediated expansion of human cord blood progenitor cells capable of rapid myeloid reconstitution. Nat Med. 2010;16(2):232-236.

8. Delaney C, Milano F, Cicconi L, Othus M, Becker PS, Sandhu V, et al. Infusion of a non-HLA-matched ex-vivo expanded cord blood progenitor cell product after intensive acute myeloid leukaemia chemotherapy: a phase 1 trial. Lancet Haematol. 2016;3(7):e330-e339.

9. Kalos M, Levine BL, Porter DL, Katz S, Grupp SA, Bagg A, et al. T cells with chimeric antigen receptors have potent antitumor effects and can establish memory in patients with advanced leukemia. Sci Transl Med. 2011:3:95ra73-95ra73

10. Maude SL, Laetsch TW, Buechner J, Rives S, Boyer M, Bittencourt H, et al. Tisagenlecleucel in children and young adults with B-cell lymphoblastic leukemia. Sci Transl Med. 2011;3(95):95ra73.

11. Neelapu SS, Locke FL, Bartlett NL, Lekakis LJ, Miklos DB, Jacobson CA, et al. Axicabtagene ciloleucel CAR T-Cell therapy in refractory large b-cell lymphoma. N Engl J Med. 2017;377(26):2531-2544.

12. Veluchamy JP, Kok N, van der Vliet HJ, Verheul HMW, de Gruijl TD, Spanholtz $\mathrm{J}$, et al. The rise of allogeneic natural killer cells as a platform for cancer immunotherapy: recent innovations and future developments. Front Immunol. 2017:8:631.

13. Rezvani K, Rouce R, Liu E, Shpall E. Engineering natural killer cells for cancer immunotherapy. Mol Ther. 2017;25(8):1769-1781.

14. Squillaro T, Peluso G, Galderisi U. Clinical trials with mesenchymal stem cells: an update. Cell Transplant. 2016;25(5):829-848. 